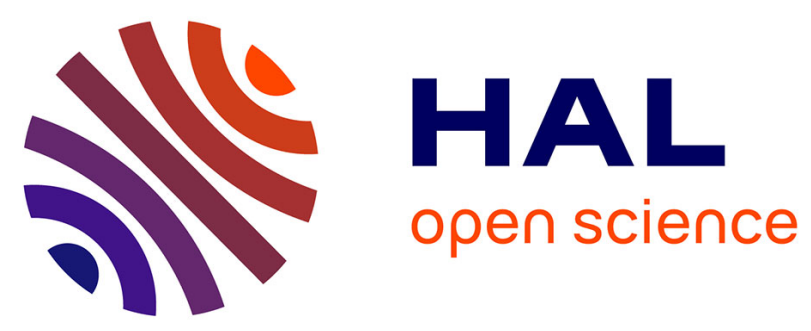

\title{
Replacing Metals with Oxides in Metal-Assisted Chemical Etching Enables Direct Fabrication of Silicon Nanowires by Solution Processing
}

Maxime Gayrard, Justine Voronkoff, Cedric Boissiere, David Montero, Laurence Rozes, Andrea Cattoni, Jennifer Péron, Marco Faustini

\section{To cite this version:}

Maxime Gayrard, Justine Voronkoff, Cedric Boissiere, David Montero, Laurence Rozes, et al.. Replacing Metals with Oxides in Metal-Assisted Chemical Etching Enables Direct Fabrication of Silicon Nanowires by Solution Processing. Nano Letters, In press, 10.1021/acs.nanolett.1c00178 . hal03148579

\section{HAL Id: hal-03148579 \\ https: / hal.sorbonne-universite.fr/hal-03148579}

Submitted on 22 Feb 2021

HAL is a multi-disciplinary open access archive for the deposit and dissemination of scientific research documents, whether they are published or not. The documents may come from teaching and research institutions in France or abroad, or from public or private research centers.
L'archive ouverte pluridisciplinaire HAL, est destinée au dépôt et à la diffusion de documents scientifiques de niveau recherche, publiés ou non, émanant des établissements d'enseignement et de recherche français ou étrangers, des laboratoires publics ou privés. 


\section{Replacing Metals with Oxides in Metal-Assisted}

\section{Chemical Etching Enables Direct Fabrication of}

\section{Silicon Nanowires by Solution Processing}

Maxime Gayrard, ${ }^{1}$ Justine Voronkoff, ${ }^{1}$ Cédric Boissière, ${ }^{1}$ David Montero, ${ }^{2}$ Laurence Rozes, ${ }^{1}$ Andrea Cattoni, ${ }^{3}$ Jennifer Peron, ${ }^{4}$ Marco Faustini ${ }^{1^{*}}$

1 Sorbonne Université, CNRS, Collège de France, Laboratoire Chimie de la Matière Condensée de Paris (LCMCP), F-75005 Paris, France

2 Sorbonne Université, Institut des Matériaux de Paris Centre (IMPC FR 2482), UFR de Chimie Campus Jussieu, 75252 Paris, France

3 Centre de Nanosciences et de Nanotechnologies (C2N), CNRS UMR 9001, Université ParisSaclay, Palaiseau, France.

4 Université de Paris, ITODYS, CNRS, UMR 7086, 15 rue J-A de Baïf, F-75013 Paris, France

e-mail: marco.faustini@sorbonne.universite.fr 
KEYWORDS Metal Assisted Chemical Etching, Oxides, Nanofabrication, Sol-Gel, Nanoimprint, Block-copolymer

\section{ABSTRACT}

Metal-Assisted Chemical Etching (MACE) has emerged as effective method to fabricate high aspect ratio nanostructures. This method requires a catalytic mask that is generally composed by a metal. Here, we challenge the general view that the catalyst needs to be metal by introducing Oxide-assisted Chemical Etching (OACE). We perform etching with metal oxides such as $\mathrm{RuO}_{2}$ and $\mathrm{IrO}_{2}$, by transposing materials used in electrocatalysis to nanofabrication. These oxides can be solution-processed as polymers exhibiting similar capabilities of metals for MACE. Nanopatterned oxides can be obtained by direct nanoimprint lithography or blockcopolymer lithography from chemical solution on large scale. High aspect ratio silicon nanostructures were obtained at the sub-20 nm scale exclusively by cost-effective solution processing by halving the number of fabrication steps compared to MACE. More in general, OACE is expected to stimulate new fundamental research on chemical etching assisted by other materials providing new possibilities for device fabrication. 


\section{Introduction}

The fabrication of high aspect ratio silicon nanostructures is of high interest for a number of applications including photovoltaics, ${ }^{1,2} 3 \mathrm{D}$ transistors, ${ }^{3}$ batteries, ${ }^{4}$ sensing, ${ }^{5}$ optics, ${ }^{6}$ wetting, ${ }^{7}$ catalysis $^{8}$ and microfluidics. ${ }^{9}$ Metal assisted chemical etching (MACE) has emerged as a convenient alternative to dry etching ${ }^{10,11}$ to prepare large-scale surfaces by a low cost, wet etching method. ${ }^{12,13}$ The mechanism is based on a chemical etching in solution that is catalyzed when a noble metal is in contact with the Si surface. ${ }^{14}$ The etchant solution is composed of HF and an oxidative agent, typically $\mathrm{H}_{2} \mathrm{O}_{2}$. The noble metal sinks into the substrate, generating deep Si nanostructures with geometry depending on the initial morphology of the noble metal layer. This process is widely used to obtain silicon nanowires but it was also extended to other semiconducting materials such as $\mathrm{Ge}, \mathrm{GaAs}^{15}$ and $\operatorname{In} \mathrm{P}^{16}$ with important implications for solarcells for instance. The MACE process is now well established in the nanofabrication community and its complex mechanism is still a matter of scientific debate to understand the role of each component (metal, etchant, oxidant, semiconductor...). ${ }^{17}$ In addition some technological challenges need to be tackled, especially for the preparation sub-micrometric features at large scale by fabrication processes with a limited number of steps. By definition the etching catalyst in MACE is a metal, typically gold, silver or platinum. The preparation of high aspect ratio well defined features requires the fabrication of a "negative" noble metal mask. For instance, arrays of nanowires are made from perforated noble metal layers. The fabrication of well-defined metallic etching masks requires multiple steps, typically involving patterning of an intermediate material (resist), deposition of the metal and lift-off process. Lift-off processes require a break in the gold film after deposition on resist features. This multistep process is especially 
challenging for the fabrication of sub-100 $\mathrm{nm}$ nanostructures. In addition, some common noble metals films have poor chemical $(\mathrm{Ag})$ or/and thermal stability and have the tendency to de-wet if annealed at relatively low temperature. In order to fulfill the requirements for a further scaleup and industrialization, developing of a simpler and robust way to fabricate etching mask would be strongly beneficial. An interesting approach based on the direct electrochemical imprinting of silicon (called Mac-Imprint) was recently introduced. It uses a patterned polymer stamp coated with a noble metal catalyst to etch silicon in contact with the stamp by MACE. ${ }^{18} 19$ While this method is appealing, it is not suited for the fabrication of high aspect ratio Si nanostructures because the catalytic stamp cannot sink into the silicon substrate. An ideal option would consist in replacing the catalytic metals with other materials that can be directly processed and patterned as a polymer by solution processing. However, this alternative has not been widely considered because the general view is that, in MACE, the catalyst is a metal. Recently, alternative catalytic materials have been proposed including graphene, ${ }^{20}$ graphene oxide, ${ }^{21}$ carbon nanotubes ${ }^{22}$ or titanium nitride. ${ }^{23}$ However, these alternative processes require multistep pattern transfer as in the case of metals and are generally less effective than MACE for the fabrication of high aspect ratio structures. From a chemical point of view an efficient mask for MACE should be: (i) a good catalyst for the involved electrochemical reactions (ii) a conductive material to allow holes migrations, (iii) a stable material in harsh etching conditions. Interestingly, these requirements present striking analogies with those needed for electrocatalysts used for the oxygen evolution reaction. In the latter case, the most efficient materials are not noble metals but oxides. ${ }^{24}$ For instance, $\mathrm{RuO}_{2}$ and $\mathrm{IrO}_{2}$ are known to be excellent electrocatalyts, conductive and stable in extremely oxidative conditions. ${ }^{25} \mathrm{RuO}_{2}$ and 
$\mathrm{IrO}_{2}$ present working function $>5 \mathrm{eV}^{26}$ similar to those of metals $(5.1 \mathrm{eV}$ and $4.26 \mathrm{eV}$ for $\mathrm{Au}$ and $\mathrm{Ag}$ respectively) ${ }^{27}$ but higher oxidation number (IV). For $\mathrm{RuO}_{2}$, the redox potential with its oxidized counterpart $\mathrm{RuO}_{4} / \mathrm{RuO}_{2}$ is $1.2-1.3 \mathrm{~V},{ }^{28}$ a value between those of $\mathrm{Au}^{3+} / \mathrm{Au}(1.5 \mathrm{~V})$ and $\mathrm{Ag}^{+} / \mathrm{Ag}(0.8 \mathrm{~V}) .^{27}$ In addition, it has been recently reported that they can be prepared by chemical methods enabling direct shaping into porous spheres ${ }^{29,30}$ or films. $^{31-33}$ In this work, bridging research on electrocatalysts and MACE processing, we introduce Oxide-Assisted Chemical Etching (OACE), in which the metallic mask is replaced by an oxide counterpart. We show that $\mathrm{RuO}_{2}$ and $\mathrm{IrO}_{2}$ nanopatterned films can be obtained by a "sol-gel process" directly from solution deposition. Morphological and compositional evolution of the oxide layers were characterized by in-situ ellipsometry, Scanning Electron Microscopy, Atomic Force Microscopy and X-Ray Photoelectron Spectroscopy (XPS). We demonstrate the versatility of the approach by implementing two different patterning methods for noble metal oxides both characterized by a limited number of fabrication steps: direct soft-nanoimprint lithography and blockcopolymer micellar lithography. High aspect ratio silicon nanostructures are obtained with lateral dimensions down to the sub-20 nm scale by halving the number of fabrication steps with respect to previous approaches based on MACE. Importantly, this work extends the compositional threshold of the catalyst for chemical etching beyond metals. This report will trigger new fundamental research on chemical etching assisted by other materials providing new possibilities for device fabrication.

\section{Results and discussion}

\subsection{Soft-Nanoimprinting Lithography}


As a case of study, we describe the fabrication of $\mathrm{Si}$ nanostructured by OACE using $\mathrm{RuO}_{2}$ masks fabricated by direct soft-nanoimprinting lithography of a sol-gel derived film. A schematic illustration of the process is reported in Figure 1. The film is applied by dip-coating deposition from $\mathrm{RuCl}_{3} \mathrm{xH}_{2} \mathrm{O}$ dissolved in hydro-alcoholic solution. Due to hygrocopic nature of the Ru salts, the dip-coating process was performed in controlled atmosphere to keep the relative humidity below $10 \% \cdot{ }^{34}$ The initial film thickness after dip-coating was around $180 \mathrm{~nm}$ as determined by spectroscopic ellipsometry. After evaporation of the solvent, the film is immediately embossed by patterned PDMS-based stamp previously degassed in vacuum. The layer is stabilized at $130^{\circ} \mathrm{C}$ before demolding. The imprinting process is pressure-less, does not require any imprinting equipment and can be realized on large scale. ${ }^{35-37}$ Figure S1 in Supplementary Material displays the photo of a patterned sample of $4 \mathrm{~cm}^{2}$ exhibiting areas with different iridescent colors characteristic of diffractive gratings with periodicities ranging from 400 to $1000 \mathrm{~nm}$. 
Soft-Nanoimprint Lithography

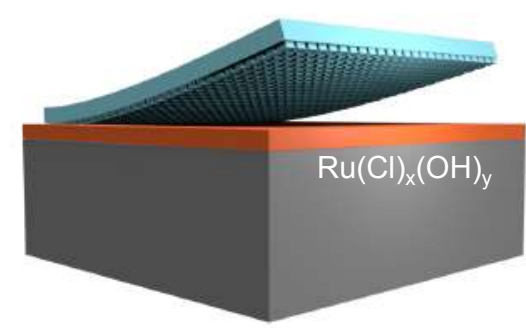

Dip-coating

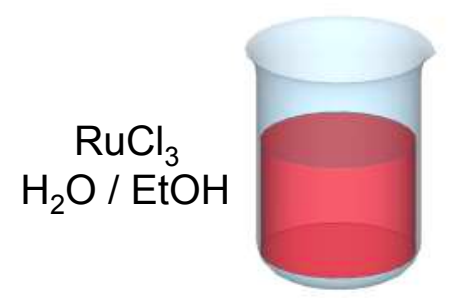

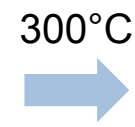
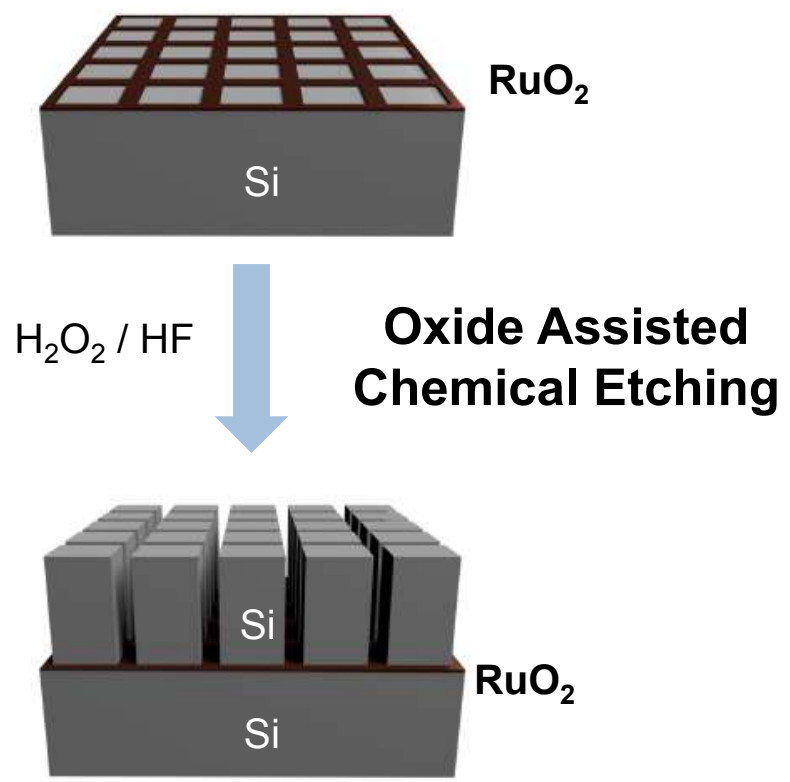

Figure 1 Scheme of the fabrication of silicon nanowires fabricated by Oxide Assisted Chemical Etching from $\mathrm{RuO}_{2}$ masks with squared nanoholes obtained by direct soft-nanoimprinting lithography

The film is then converted to $\mathrm{RuO}_{2}$ by thermal treatment in air at temperature above $225^{\circ} \mathrm{C}$. The final etching step is then performed in a $\mathrm{HF} / \mathrm{H}_{2} \mathrm{O}_{2}$ solution by using the $\mathrm{RuO}_{2}$ catalytic mask. The different steps of the fabrication process have been investigated for masks composed of arrays of squared perforations at the sub-micrometric scale. Figure 2(a) and (b) display the SEM-FEG micrographs of the mask after thermal treatment at $300^{\circ} \mathrm{C}$. One of the common drawbacks of the films patterned by nanoimprinting lithography is that a residual layer remains 
after embossing and an additional step of dry-etching is required to complete the lithography process.
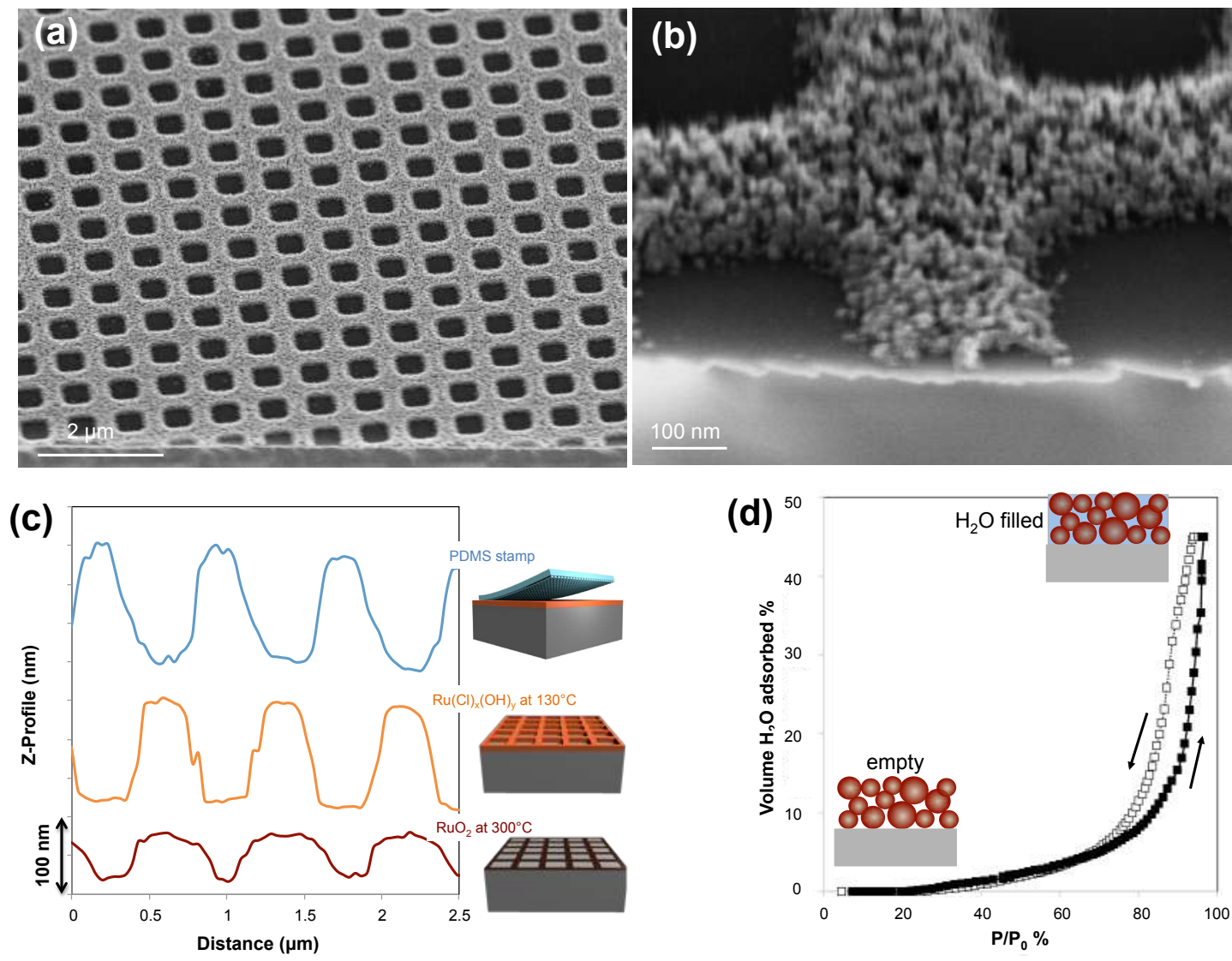

Figure 2 Scanning Electron micrographs of the $\mathrm{RuO}_{2}$ layer after thermal treatment at $300^{\circ} \mathrm{C}$ at (a) lower magnification and (b) higher magnification. (c) Atomic Force Microscopy Z-profiles of the PDMS stamp, of the patterned layer after demolding and after annealing at $300^{\circ} \mathrm{C}$. (d) Adsorption/desorption curves of the $\mathrm{RuO}_{2}$ plain film obtained by Environmental Ellipsometric Porosimetry.

Very interestingly, in these conditions (initial thickness $<200 \mathrm{~nm}$ ), the Ru-based layer patterned films do not present a residual layer in the entire surface as displayed in Figure 2(b). The 
absence of the residual layer was also observed for other geometries such as grooves or triangular holes. (Figure S2 in Supplementary Material). This can be attributed to the poor affinity between the $\mathrm{Ru}(\mathrm{Cl})_{x}(\mathrm{OH})_{y}$ films and the silicon substrate that enhance the mobility of the Ru species during imprinting. The efficiency of the imprinting process was further investigated by Atomic Force Microscopy. Figure 2(c) shows a good correspondence between the Z-profiles of the original PDMS stamp and patterned layer after stabilization at $130^{\circ} \mathrm{C}$ (and demolding). The profile of the $\mathrm{RuO}_{2}$ sample annealed at $300^{\circ} \mathrm{C}$ indicates a significant shrinkage in the perpendicular direction (around 50\%). The thermal treatment induces volumetric shrinkage and crystallization of the $\mathrm{RuO}_{2}$ film leading to a conductive nanoparticle-based film. These two effects have been investigated by in-situ spectroscopic ellipsometry on a plane film during the thermal treatment. ${ }^{38}$ The experiment was performed into an environmental chamber by heating in air the sample from room temperature up to $300^{\circ} \mathrm{C}$. Since the material is evolving during thermal treatment, two models have been used for the thermal ellipsometric analysis. A first model for temperatures below the crystallization describing non-conductive layer composed of Lorentz oscillators to describe the absorption of the material especially in the visible range (Figure S3 in Supplementary Material). ${ }^{39}$ For temperature above the crystallization, a second model was used: in addition to the Lorentz oscillators, a Drude model was added to describe the optical properties that are characteristic for conductive films (Figure S4 in Supplementary Material). Starting from these models, a full analysis was then performed. The evolution of the thickness is reported in Figure 3(a). After deposition, a large shrinkage of the film is observed by heating the material from room temperature to $150^{\circ} \mathrm{C}$. This thickness contraction can be attributed to the loss of adsorbed water leaving the $\mathrm{Ru}(\mathrm{Cl})_{x}(\mathrm{OH})_{y}$ species 
that, at room temperature, are highly hygroscopic. A second contraction is observed between $200^{\circ} \mathrm{C}$ and $220^{\circ} \mathrm{C}$ corresponding to the formation of the $\mathrm{RuO}_{2}$. The layer is made of $\mathrm{RuO}_{2}$ nanocrystals having rutile structure as confirmed by X-Ray diffraction as shown in Figure S5 in Supplementary Material.
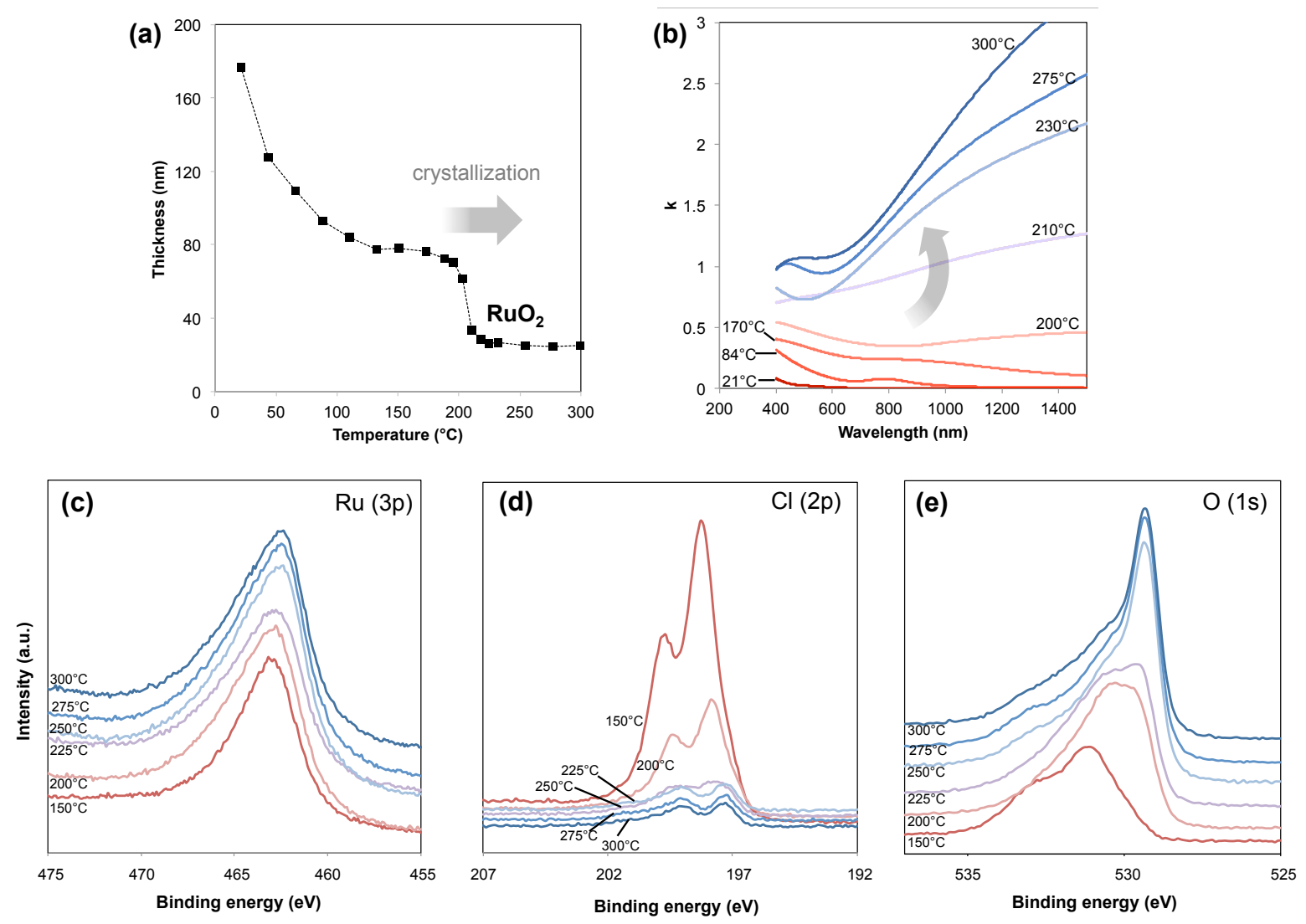

Figure 3 In situ thermal ellipsometric analysis: (a) evolution of the thickness as function of the temperature; (b) evolution of the extinction coefficient $k$ with the temperature: the insulatingconductive transition is observed between 200 and $230^{\circ} \mathrm{C}$. XPS spectra recorded in the $\mathrm{Ru}(3 p)$ region (c), $\mathrm{Cl}(2 \mathrm{p})$ region (d), and $\mathrm{O}(1 \mathrm{~s})$ region (e) on films calcined at different temperatures.

The diffractogram of the layer calcined at $300^{\circ} \mathrm{C}$ displays the characteristic peaks of the rutile phase having average size of $15 \mathrm{~nm}$ as determined by Scherrer equation ${ }^{40}$ (Figure S5 in 
Supplementary Material). The transformations occurring during thermal treatment could be confirmed by monitoring the evolution of the extinction coefficient $(k)$ as function of wavelength and temperature as obtained by the ellipsometric fit. This evolution is reported in Figure 3(b). Below crystallization, the film presents low value of $k$, especially at low wavelength in the visible range that increases with the temperature. This can be attributed to the presence of colored Ru complexes in the film, for which the $\mathrm{k}$ values increase as the volume decreases. Starting from $200^{\circ} \mathrm{C}$ the value of $\mathrm{k}$ drastically increases especially in the near infrared region; this behavior is characteristic of the formation of a conductive film. The chemical transformations can also be followed by XPS. $\mathrm{Ru}(3 p), \mathrm{Cl}(2 p)$ and $\mathrm{O}(1 \mathrm{~s})$ core-level spectra of samples calcined from $150^{\circ} \mathrm{C}$ to $300^{\circ} \mathrm{C}$ are displayed in Figure $3(\mathrm{c})$, (d), and (e), respectively. Since $\mathrm{Ru}(3 \mathrm{~d})$ core levels superimpose the $\mathrm{C}(1 \mathrm{~s})$ core level, the $\mathrm{Ru}(3 \mathrm{p})$ region was analyzed. As an electron conductor, $\mathrm{RuO}_{2}$ has an asymmetric core level spectra and for this reason, highly reliable quantification of the Ru oxidized species (Ru(IV), $R u(I I I))$ using XPS is challenging and caution is required. However, from Ru (3p) spectra plot in Figure 3(c), we can see that the $\mathrm{Ru}(3 p)$ peak shifts progressively from $463.1 \mathrm{eV}$ to $462.6 \mathrm{eV}$ when the calcination temperature is increased from $150^{\circ} \mathrm{C}$ to $225^{\circ} \mathrm{C}$. From $225^{\circ} \mathrm{C}$ to $300^{\circ} \mathrm{C}$, the $\mathrm{Ru}(3 \mathrm{p}$ ) signal remains at the same position, $462.6 \mathrm{eV}$, being characteristic of $\mathrm{Ru}(\mathrm{IV})$ into $\mathrm{RuO}_{2} \cdot{ }^{41}$ Concomitantly to shift observed for $\mathrm{Ru}(3 p)$ signals, the peaks characteristic of the $\mathrm{Cl} 2 p 3 / 2$ and $2 p 1 / 2$ initially located at 198.3 $\mathrm{eV}$ and $199.7 \mathrm{eV}$ shifts towards lower values down to $197.3 \mathrm{eV}$ and $198.7 \mathrm{eV}$, respectively (Figure 3d). This shift is accompanied by a strong decrease in the $\mathrm{Cl}$ signal intensity, $\mathrm{Cl} / \mathrm{Ru}$ atomic ratio decreases from $c a .3$ down to $c a .0 .3$ when the calcination temperature is increased from $150^{\circ} \mathrm{C}$ to $250^{\circ} \mathrm{C}$. Finally, the spectra in Figure $3(\mathrm{e})$ indicates that the transition 
from hydroxylated species into metal-oxygen bonds occurs in the same temperature range since the intensity of the $\mathrm{O}(1 \mathrm{~s})$ component located at $531 \mathrm{eV}$ for the sample calcined at $150^{\circ} \mathrm{C}$ and characteristic of $\mathrm{M}-(\mathrm{OH})$ bonds decreases at the expense of the peak centered at $529.3 \mathrm{eV}$ and characteristic of M-O bond in metal oxides. From XPS analysis, we confirm that the transition from $\mathrm{Ru}(\mathrm{III})$ into $\mathrm{Ru}(\mathrm{IV})$ occurs simultaneously as the departure of chlorine and the formation of $\mathrm{Ru}-\mathrm{O}$ bonds, and, the transition from $\mathrm{Ru}(\mathrm{III})$ into $\mathrm{RuO}_{2}$ is complete at $225^{\circ} \mathrm{C}$, in agreement with thermal ellipsometric analysis. As already shown in SEM photos in Figure 3(d) the $\mathrm{RuO}_{2}$ patterned films are thus composed by a network of percolated conductive $\mathrm{RuO}_{2}$ nanocrystals with inter-particle porosity. The porosity was investigated by environmental ellipsometric porosity on unpatterned films (detailed analysis in S6 and S7 Supplementary Material). ${ }^{42} 43$ In Figure 2 (d), the adsorption/desorption isotherm reveals a large increase of \% vol of water adsorbed between between $70 \%$ and $100 \% \% P / P_{0}$ due to the capillarity condensation of water vapor in the pores corresponding to the interparticle voids. The porous volume and avarage pore size were quantified to be $45 \%$ and $12 \mathrm{~nm}$ in agreement with SEM observations. The presence of the nanoporosity is not a drawback in the MACE process. As demonstrated for noble metals, using a nanoporous catalyst is beneficial for the etching process $^{44}$ enabling access of the hydrofluoric acid to the silicon surface. The $\mathrm{RuO}_{2}$ masks fabricated by direct nanoimprint lithography were then used as catalyst for the OACE of silicon. As an example Figure 4(a) and (c) represent SEM micrographs of a single $\mathrm{RuO}_{2}$ nanotrench before and after chemical etching respectively. This geometry allows cross-section visualization of the inner structure of Si after etching. From Figure 4(c) and Figures S8 in Supplementary Material, no porosity is visible by SEM or TEM in both the Si nanotrenchs, nanowires and in the 
Si substrate underneath the $\mathrm{RuO}_{2}$ mask. After etching, the $\mathrm{RuO}_{2}$ catalytic mask is located at the bottom of the Si trench confirming that during the reaction the $\mathrm{RuO}_{2}$ maintains an intimate electrical contact with the silicon, sinking with the silicon as it is etched.
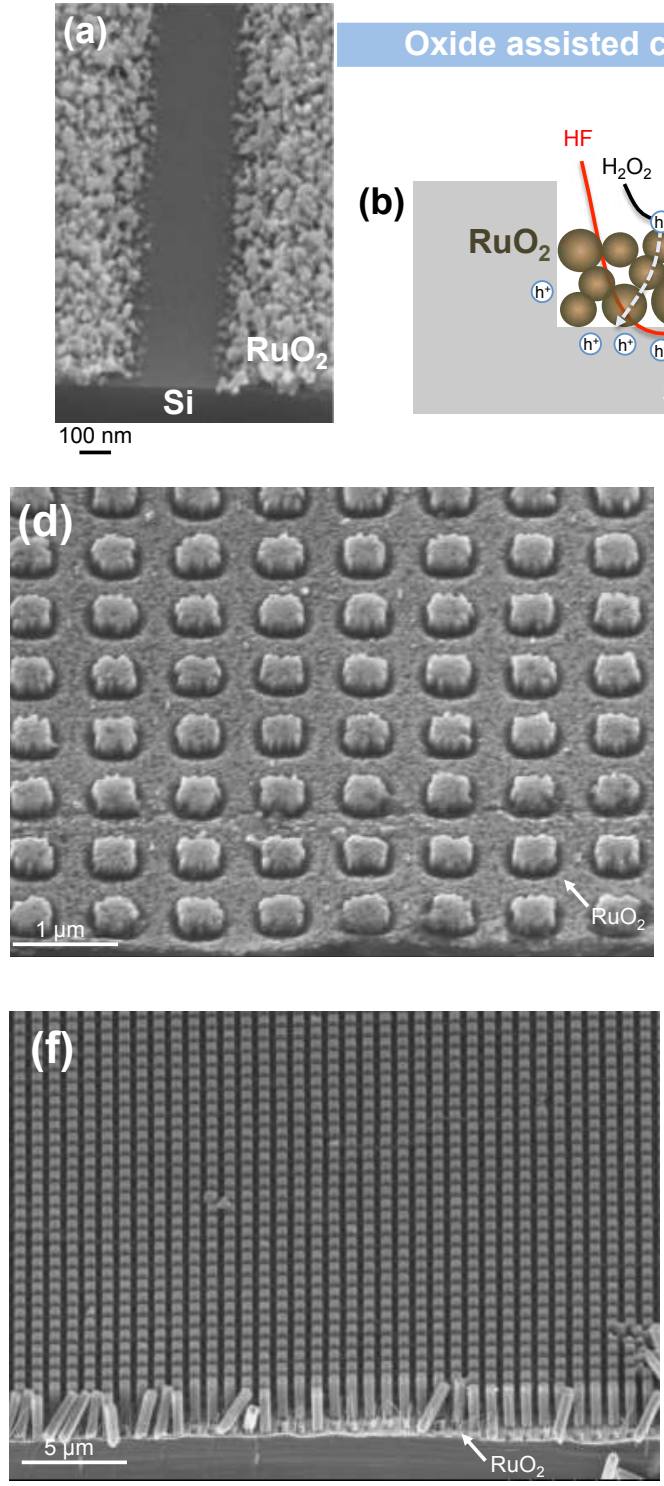
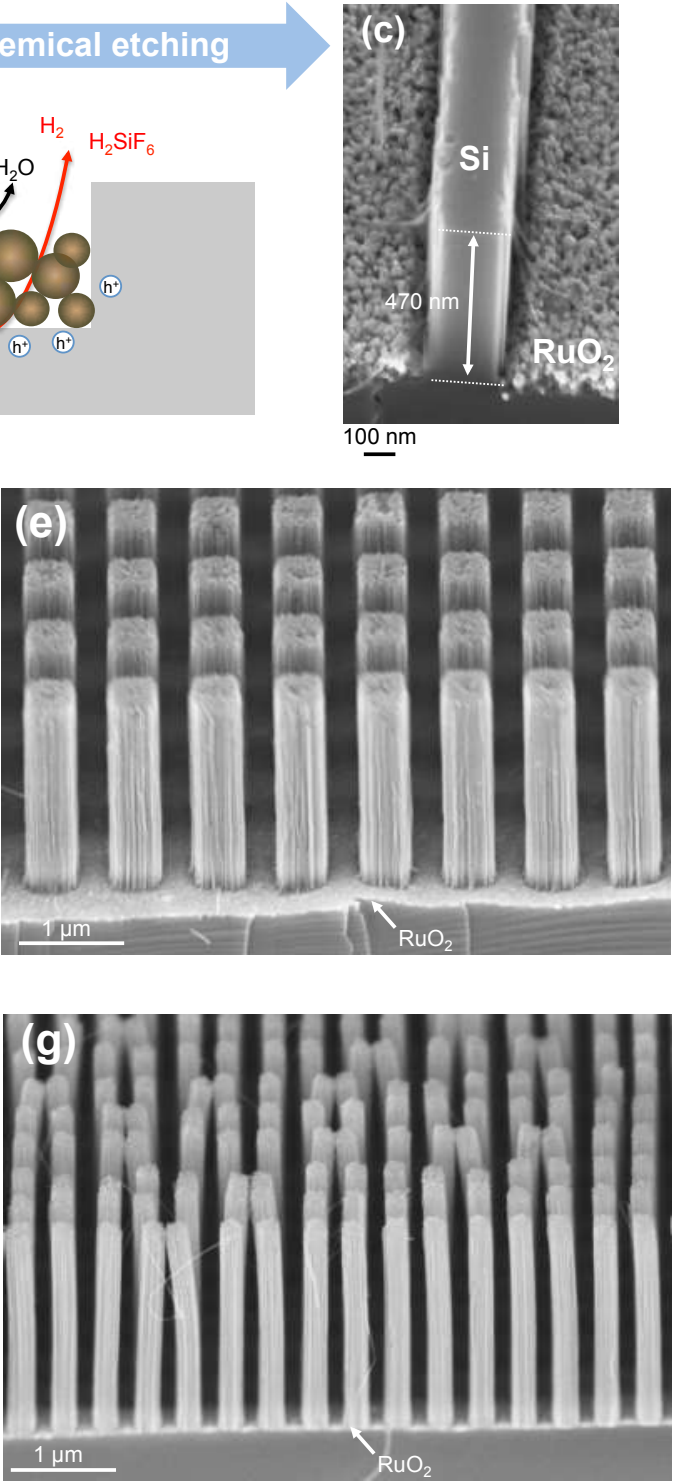

Figure 4 Scanning Electron micrographs of (a) $\mathrm{RuO}_{2}$ nanochannel and (c) silicon nanotrench after oxide assisted chemical etching. (b) Scheme of the proposed OACE mechanism. (d) and (e) SEM micrographs of $485 \mathrm{~nm}$ sized silicon nanowires obtained after $30 \mathrm{~s}$ and 5 minutes of 
etching (f) lower magnification SEM of the sample shown in (e). (g) SEM of 230nm sized silicon nanowires obtained after 5 minutes of etching.

In our experiment, we employed a typical composition for etching solution containing $\mathrm{H}_{2} \mathrm{O}_{2}$ and HF on a p-doped (boron) Si wafer (100). Immediately after immersion in the etching solution, bubbles developed from the surfaces. Indeed both compounds are needed for the process to take place. Without $\mathrm{H}_{2} \mathrm{O}_{2}$, no etching and bubble formation was observed. In contrast, delamination of the $\mathrm{RuO}_{2}$ layer is observed after several minutes in solution containing only $\mathrm{HF}$, probably due to the presence of a thin $\mathrm{SiO}_{2}$ layer formed on the $\mathrm{Si}$ substrate during thermal treatment. This observations suggest that, in our conditions, the mechanism of Oxide-Assisted Chemical Etching doesn't different significantly from the typical Metal-Assisted Chemical Etching. The proposed mechanism is thus illustrated in Figure 4 (b). Figures $4(e)$ and (f) show SEM micrographs at different magnification of the sample composed of silicon nanopillars arrays having periodicity of $1000 \mathrm{~nm}$ obtained after 5 minutes etching. The pillars display an average size of $485 \mathrm{~nm}$ and a height of $1750 \mathrm{~nm}$. The same experiment was performed on an array with smaller dimensions and lower etching time as shown in Figure $4(\mathrm{~g})$ and (d). In this case, the pillar size and height are respectively $230 \mathrm{~nm}$ and $1900 \mathrm{~nm}$ resulting in aspect ratio above 8 . In case of elongated nanostructures, some pairs of pillars show typical clustering caused by capillary forces upon drying and electrostatic interactions. ${ }^{45}$ Finally, the same process was reproduced on patterns with different geometries including triangular grooves or triangular pillars (Figure S2 in Supplementary Material). Due to polycrystalline nature of the $\mathrm{RuO}_{2}$ and to the relatively large crystal size at $300^{\circ} \mathrm{C}$, the Line-Edge Roughness (LER) on the pattern is quite high. The LER can be reduced by limiting the crystal growth using a 
lower annealing temperature. This is especially important for the fabrication high aspect ratio nanostructures with higher resolution as shown in the following.

\subsection{Block-Copolymer Micellar Lithography}

To confirm the versatility of the approach including for high-resolution nanofabrication at the sub-20nm scale a new method for the fabrication of the etching mask is proposed based on block-copolymer micellar nanolithography. This strategy to obtain nanoperforated ceramic layers was already developed for common metal oxides such as $\mathrm{TiO}_{2}{ }^{46}$ but never demonstrated for noble metal oxides so far.
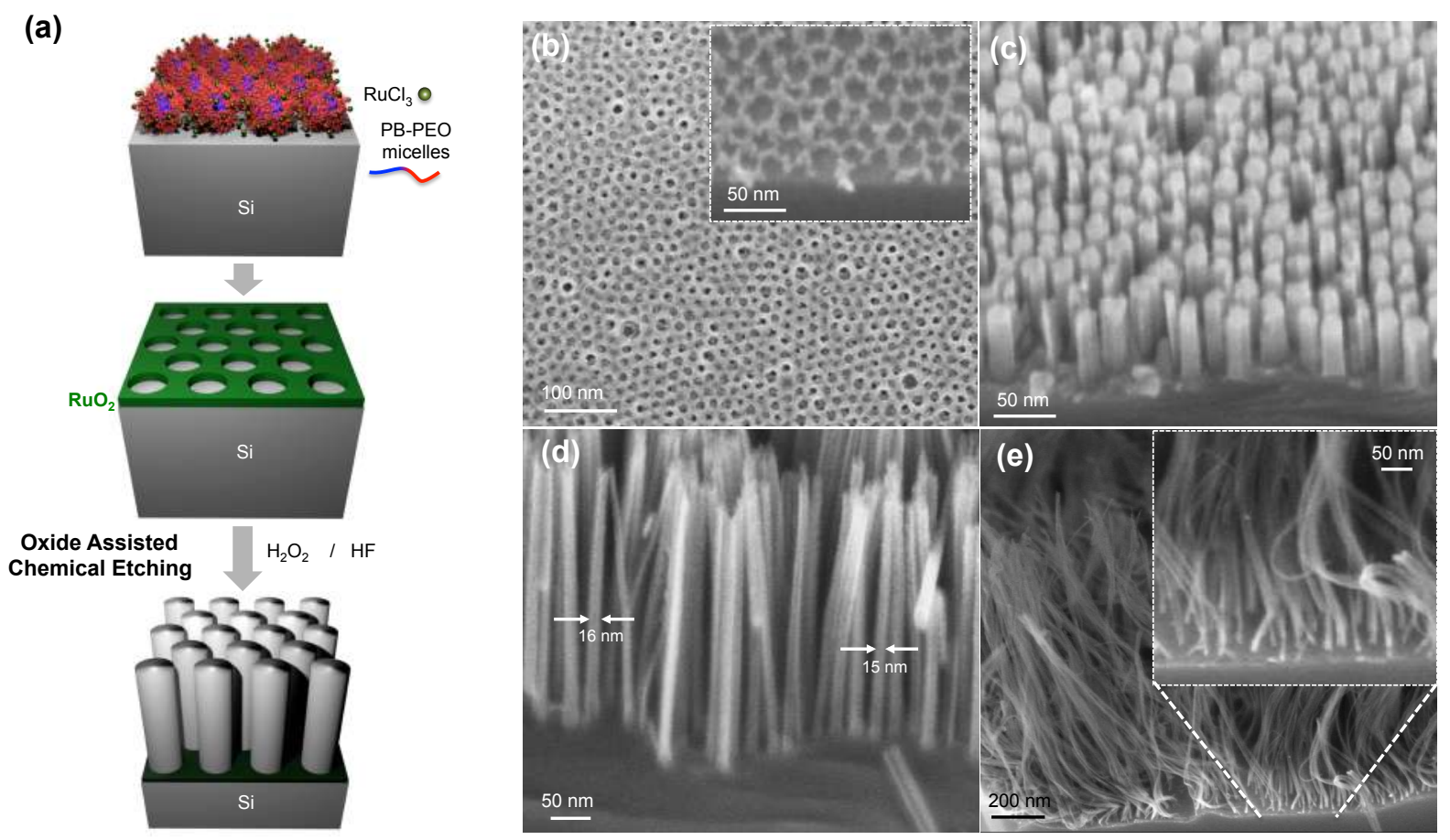

Figure 5 (a) Nanofabrication scheme based on block-copolymer micellar lithography and Oxide assisted chemical etching. (b) block-copolymer templated $\mathrm{RuO}_{2}$ layer before etching. (c), (d) and (e) Sub-20 nm silicon nanowires obtained after 1, 5, 30 minutes of etching respectively. 
The fabrication scheme is illustrated in Figure 5(a). A PB-PEO block-copolymer (15 $600 \mathrm{~g} \mathrm{~mol}^{-1}$ $\left(\mathrm{PB}_{112} \mathrm{PEO}_{227}\right)$ was first dissolved in a hydro-alcoholic solution in presence of $\mathrm{RuCl}_{3}$. In these conditions, the block-copolymer form micelles having a hydrophobic PB core and a hydrophilic PEO shell. ${ }^{47} \mathrm{~A}$ film is then obtained on the silicon substrate by dip-coating from this solution. The deposition conditions were adjusted to obtain a monolayer of micelles that are surrounded by the Ru precursor. The film was then heated at $250^{\circ} \mathrm{C}$ in air to decompose the PB-PEO blockcopolymer ${ }^{46}$ and convert the $\mathrm{Ru}\left(\mathrm{Cl}_{x} \mathrm{OH}_{\mathrm{y}}\right)$ species into conductive $\mathrm{RuO}_{2}$. After annealing the $\mathrm{RuO}_{2}$ film is composed of pores having diameter of $20 \mathrm{~nm}$ and periodicity of around $50 \mathrm{~nm}$ as shown in the SEM micrograph in Figure $5(b)$. In order to limit the crystal growth, the calcination temperature was optimized. A thermal treatment at $250^{\circ} \mathrm{C}$ for 30 seconds was found to be the best compromise to ensure conversion to metal-like $\mathrm{RuO}_{2}$ while retaining the surface nanostructuration. As shown in the SEM micrographs in Figure S9 in Supplementary Material, annealing at higher temperatures or for longer times resulted in crystal growth progressive loss of the nanofeatures. The SEM micrographs in Figure $5 \mathrm{c}$, $d$ and e display the samples after Oxide-Assisted Chemical Etching for 1, 5, 30 minutes respectively. The etching process results in sub-20 $\mathrm{nm}$ silicon nanowires (as dictated by the initial perforation size) with length that increases pseudo-linearly as function of the etching time (Figure S10 in Supplementary Material). Notably, the silicon nanowires obtained after 30 minutes etching display lengths exceeding 1.2 micrometers corresponding to aspect ratio above 60. As shown in Figure S10, the etching rate of $\mathrm{RuO}_{2}$ is higher than conventional electroplated $\mathrm{Ag}$ in the same etching conditions (composition, substrate). While this observation confirms the efficiency of $\mathrm{RuO}_{2}$ as etching materials, more systematic studies are needed to compare the etching rate of oxides 
with respect to metals in optimized etching conditions and with similar mask geometry. The OACE is not limited to $\mathrm{RuO}_{2}$. Following the same principles other oxides used as electrocatalysts could be envisioned. Among them, IrOx is another of the most active and stable electrocatalyst for the oxygen evolution reaction. Figure S11 ( $a$ and b) in Supplementary Material report the fabrication of sub 20-nm nanowires arrays obtained by OACE starting from IrOx nanomasks. As detailed previously, the masks were prepared by block-copolymer micellar lithography in presence of $\mathrm{IrCl}_{3}$. After deposition a thermal treatment at $375^{\circ} \mathrm{C}$ was applied since the formation of iridium oxide occurs at higher temperatures as respect to ruthenium oxide. ${ }^{22}$ We further demonstrate that the size of the nanowires can be tuned by applying same method but with PB-PEO block-copolymers with higher molecular length (75 $500 \mathrm{~g} \mathrm{~mol}^{-1} \mathrm{~PB}_{640} \mathrm{PEO}_{989}$ ) resulting in perforations and nanowire's size of $60 \mathrm{~nm}$ (Figure S11 c and d in Supplementary Material).

\section{Conclusions and perspectives}

Summarizing, in this contribution we show that solution-processed oxides can replace metallic catalysts in Metal-Assisted Chemical Etching for nanofabrication of silicon nanowires. The concept was demonstrated with $\mathrm{RuO}_{2}$ and $\mathrm{IrO}_{2}$ whose conductivity, stability and catalytic properties area already exploited in other fields such as electrocatalysis. From an applicative point of view, we show here that nanostructured oxides can be obtained by solution-processing and directly patterned to fabricate catalytic masks for etching on large scale. The versatility of the approach was demonstrated by applying two high-throughput, low-cost patterning methods: direct soft-nanoimprinting lithography of sol-gel based films and block-copolymer 
micellar lithography. In particular, fabrication of sub-20 nm silicon nanowires was achieved by OACE meeting the current state of the art of MACE in terms of resolution yet by reducing by half the number of nanofabrication steps. This gain is shown in Figure S12 in Supplementary Material by comparing our approach with a previously reported nanofabrication scheme to prepare sub-20 nm SiNWs by block-copolymer lithography coupled with MACE ${ }^{48}$. By our approach, the fabrication of the mask and of the silicon nanowires is carried exclusively by costless solution processing and does not require dedicated equipment such as reactive ion etching or sputtering. In perspective, the preparation of the oxide catalytic layers can also be extended to other solution processing methods (spray or spin coating, ink-jet, roll-to-roll printing) or to other technologies such as electroplating or chemical vapor deposition. This method could also be extended to other oxides or multimetallic oxides in which composition, porosity, doping or crystallinity can be tuned to control the etching rate or quality. More generally, these results extend the compositional threshold of the catalysts used for MACE opening interesting perspectives in terms of basic research on catalytic etching applied to nanofabrication.

\section{ASSOCIATED CONTENT}

Materials and Methods are included in Supporting Information

AUTHOR INFORMATION

\section{Corresponding Author}

marco.faustini@sorbonne-universite.fr 


\section{Author Contributions}

The manuscript was written through contributions of all authors. All authors have given approval to the final version of the manuscript.

\section{Funding Sources}

This work was supported by French state funds managed by the National Research Agency (ANR) through the MetaFleSS project, grant no. ANR-17-CE09-0027. The work was also partially supported by the French RENATECH network.

\section{ACKNOWLEDGMENT}

We thank the Institut des Matériaux de Paris Centre (IMPC FR2482) for servicing FEGSEM \& EDX instrumentation and Sorbonne Université, CNRS and C'Nano projects of the Région lle-deFrance for funding.

\section{REFERENCES}

1. Li, X. Metal assisted chemical etching for high aspect ratio nanostructures: A review of characteristics and applications in photovoltaics. Current Opinion in Solid State and Materials Science 2012, 16, 71-81.

2. Narasimhan, V. K.; Hymel, T. M.; Lai, R. A.; Cui, Y. Hybrid metal-semiconductor nanostructure for ultrahigh optical absorption and low electrical resistance at optoelectronic interfaces. ACS nano 2015, 9, 10590-10597.

3. Van Olmen, J.; Mercha, A.; Katti, G.; Huyghebaert, C.; Van Aelst, J.; Seppala, E.; Chao, Z.; Armini, S.; Vaes, J.; Teixeira, R. C. In 3D stacked IC demonstration using a through silicon via first approach, 2008 IEEE International Electron Devices Meeting, IEEE: 2008; pp 1-4.

4. Chan, C. K.; Peng, H.; Liu, G.; Mcllwrath, K.; Zhang, X. F.; Huggins, R. A.; Cui, Y. Highperformance lithium battery anodes using silicon nanowires. Nature nanotechnology 2008, 3, 31-35.

5. Peng, K.-Q.; Wang, X.; Lee, S.-T. Gas sensing properties of single crystalline porous silicon nanowires. Applied Physics Letters 2009, 95, 243112. 
6. Romano, L.; Kagias, M.; Vila-Comamala, J.; Jefimovs, K.; Tseng, L.-T.; Guzenko, V. A.; Stampanoni, M. Metal assisted chemical etching of silicon in the gas phase: a nanofabrication platform for X-ray optics. Nanoscale Horizons 2020, 5, 869-879.

7. Xiu, Y.; Zhu, L.; Hess, D. W.; Wong, C. P. Hierarchical silicon etched structures for controlled hydrophobicity/superhydrophobicity. Nano letters 2007, 7, 3388-3393.

8. Yamada, Y. M. A.; Yuyama, Y.; Sato, T.; Fujikawa, S.; Uozumi, Y. A Palladium-Nanoparticle and Silicon-Nanowire-Array Hybrid: A Platform for Catalytic Heterogeneous Reactions. Angewandte Chemie 2014, 126, 131-135.

9. Ko, D.-H.; Ren, W.; Kim, J.-O.; Wang, J.; Wang, H.; Sharma, S.; Faustini, M.; Kim, D.-P. Superamphiphobic silicon-nanowire-embedded microsystem and in-contact flow performance of gas and liquid streams. ACS nano 2016, 10, 1156-1162.

10. Wu, B.; Kumar, A.; Pamarthy, S. High aspect ratio silicon etch: A review. Journal of applied physics 2010, 108, 9.

11. Faustini, M.; Drisko, G. L.; Letailleur, A. A.; Montiel, R. S.; Boissière, C.; Cattoni, A.; Haghiri-Gosnet, A. M.; Lerondel, G.; Grosso, D. Self-assembled titanium calcium oxide nanopatterns as versatile reactive nanomasks for dry etching lithographic transfer with high selectivity. Nanoscale 2013, 5, 984-990.

12. Huang, Z.; Geyer, N.; Werner, P.; De Boor, J.; Gösele, U. Metal-assisted chemical etching of silicon: a review: in memory of Prof. Ulrich Gösele. Advanced materials 2011, 23, 285-308.

13. Li, X.; Bohn, P. W. Metal-assisted chemical etching in HF/H 202 produces porous silicon. Applied Physics Letters 2000, 77, 2572-2574.

14. Faustini, M.; Drisko, G. L.; Boissiere, C.; Grosso, D. Liquid deposition approaches to selfassembled periodic nanomasks. Scripta Materialia 2014, 74, 13-18.

15. Cheung, H.-Y.; Lin, H.; Xiu, F.; Wang, F.; Yip, S.; Ho, J. C.; Wong, C.-Y. Mechanistic Characteristics of Metal-Assisted Chemical Etching in GaAs. The Journal of Physical Chemistry $C$ 2014, 118, 6903-6908.

16. Kim, S. H.; Mohseni, P. K.; Song, Y.; Ishihara, T.; Li, X. Inverse metal-assisted chemical etching produces smooth high aspect ratio InP nanostructures. Nano letters 2015, 15, 641-648.

17. Lai, R. A.; Hymel, T. M.; Narasimhan, V. K.; Cui, Y. Schottky Barrier Catalysis Mechanism in Metal-Assisted Chemical Etching of Silicon. ACS Applied Materials \& Interfaces 2016, 8, 88758879.

18. Sharstniou, A.; Niauzorau, S.; Ferreira, P. M.; Azeredo, B. P. Electrochemical nanoimprinting of silicon. Proceedings of the National Academy of Sciences 2019, 116, 1026410269.

19. Azeredo, B. P.; Lin, Y.-W.; Avagyan, A.; Sivaguru, M.; Hsu, K.; Ferreira, P. Direct Imprinting of Porous Silicon via Metal-Assisted Chemical Etching. Advanced Functional Materials 2016, 26, 2929-2939.

20. Kim, J.; Lee, D. H.; Kim, J. H.; Choi, S.-H. Graphene-assisted chemical etching of silicon using anodic aluminum oxides as patterning templates. ACS applied materials \& interfaces 2015, 7, 24242-24246.

21. Kubota, W.; Ishizuka, R.; Utsunomiya, T.; Ichii, T.; Sugimura, H. Chemical etching of silicon assisted by graphene oxide. Japanese Journal of Applied Physics 2019, 58, 050924. 
22. Wilhelm, T. S.; Kecskes, I. L.; Baboli, M. A.; Abrand, A.; Pierce, M. S.; Landi, B. J.; Puchades, I.; Mohseni, P. K. Ordered Si Micropillar Arrays via Carbon-Nanotube-Assisted Chemical Etching for Applications Requiring Nonreflective Embedded Contacts. ACS Applied Nano Materials 2019, 2, 7819-7826.

23. Kim, J. D.; Kim, M.; Chan, C.; Draeger, N.; Coleman, J. J.; Li, X. CMOS-Compatible Catalyst for MacEtch: Titanium nitride-assisted chemical etching in vapor phase for high Aspect ratio Silicon nanostructures. ACS applied materials \& interfaces 2019, 11, 27371-27377.

24. Suen, N.-T.; Hung, S.-F.; Quan, Q.; Zhang, N.; Xu, Y.-J.; Chen, H. M. Electrocatalysis for the oxygen evolution reaction: recent development and future perspectives. Chemical Society Reviews 2017, 46, 337-365.

25. Ardizzone, S.; Fregonara, G.; Trasatti, S. "Inner" and "outer" active surface of RuO2 electrodes. Electrochimica Acta 1990, 35, 263-267.

26. Han, S. Y.; Lee, J.-L. Characteristics of Schottky contacts on n-type 4H-SiC using IrO 2 and RuO 2. Journal of applied physics 2003, 94, 6159-6166.

27. Kong, L.; Dasgupta, B.; Ren, Y.; Mohseni, P. K.; Hong, M.; Li, X.; Chim, W. K.; Chiam, S. Y. Evidences for redox reaction driven charge transfer and mass transport in metal-assisted chemical etching of silicon. Scientific reports 2016, 6, 1-13.

28. Pourbaix, M.; Staehle, R. W. Electrochemical equilibria. In Lectures on electrochemical corrosion, Springer: 1973; pp 83-183.

29. Faustini, M.; Giraud, M.; Jones, D.; Rozière, J.; Dupont, M.; Porter, T. R.; Nowak, S.; Bahri, M.; Ersen, O.; Sanchez, C.; Boissière, C.; Tard, C.; Peron, J. Hierarchically Structured Ultraporous Iridium-Based Materials: A Novel Catalyst Architecture for Proton Exchange Membrane Water Electrolyzers. Advanced Energy Materials 2019, 9, 1802136.

30. Peron, J.; Faustini, M.; Giraud, M.; Rozière, J.; Jones, D. J.; Boissière, C.; Tard, C. Hollow Iridium-Based Catalysts for the Oxygen Evolution Reaction in Proton Exchange Membrane Water Electrolyzers. ECS Transactions 2017, 80, 1077-1084.

31. Ortel, E.; Reier, T.; Strasser, P.; Kraehnert, R. Mesoporous IrO2 Films Templated by PEOPB-PEO Block-Copolymers: Self-Assembly, Crystallization Behavior, and Electrocatalytic Performance. Chemistry of Materials 2011, 23, 3201-3209.

32. Mattos-Costa, F. I.; de Lima-Neto, P.; Machado, S. A. S.; Avaca, L. A. Characterisation of surfaces modified by sol-gel derived RuxIr1-xO2 coatings for oxygen evolution in acid medium. Electrochimica Acta 1998, 44, 1515-1523.

33. Sassoye, C.; Laberty, C.; Le Khanh, H.; Cassaignon, S.; Boissiere, C.; Antonietti, M.; Sanchez, C. Block-Copolymer-templated synthesis of electroactive RuO2-based mesoporous thin films. Advanced Functional Materials 2009, 19, 1922-1929.

34. Bindini, E.; Naudin, G.; Faustini, M.; Grosso, D.; Boissière, C. Critical role of the atmosphere in dip-coating process. The Journal of Physical Chemistry C 2017, 121, 1457214580.

35. Cattoni, A.; Ghenuche, P.; Haghiri-Gosnet, A.-M.; Decanini, D.; Chen, J.; Pelouard, J.-L.; Collin, S. p. $\lambda 3 / 1000$ Plasmonic Nanocavities for Biosensing Fabricated by Soft UV Nanoimprint Lithography. Nano Letters 2011, 11, 3557-3563.

36. Faustini, M.; Cattoni, A.; Peron, J.; Boissière, C.; Ebrard, P.; Malchère, A.; Steyer, P.; Grosso, D. Dynamic shaping of femtoliter dew droplets. ACS nano 2018, 12, 3243-3252. 
37. Bottein, T.; Dalstein, O.; Putero, M.; Cattoni, A.; Faustini, M.; Abbarchi, M.; Grosso, D. Environment-controlled sol-gel soft-NIL processing for optimized titania, alumina, silica and yttria-zirconia imprinting at sub-micron dimensions. Nanoscale 2018, 10, 1420-1431.

38. Louis, B.; Krins, N.; Faustini, M.; Grosso, D. Understanding Crystallization of Anatase into Binary SiO2/TiO2 Sol-Gel Optical Thin Films: An in Situ Thermal Ellipsometry Analysis. The Journal of Physical Chemistry C 2011, 115, 3115-3122.

39. Chehadi, Z.; Boissière, C.; Chanéac, C.; Faustini, M. Nanoconfined water vapour as a probe to evaluate plasmonic heating. Nanoscale 2020, 12, 13368-13376.

40. Muniz, F. T. L.; Miranda, M. A. R.; Morilla dos Santos, C.; Sasaki, J. M. The Scherrer equation and the dynamical theory of X-ray diffraction. Acta Crystallographica Section A: Foundations and Advances 2016, 72, 385-390.

41. Morgan, D. J. Resolving ruthenium: XPS studies of common ruthenium materials. Surface and Interface Analysis 2015, 47, 1072-1079.

42. Li, R.; Faustini, M.; Boissière, C. d.; Grosso, D. Water capillary condensation effect on the photocatalytic activity of porous TiO2 in air. The Journal of Physical Chemistry C 2014, 118, 17710-17716.

43. Li, R.; Boudot, M.; Boissière, C.; Grosso, D.; Faustini, M. Suppressing structural colors of photocatalytic optical coatings on glass: the critical role of SiO2. ACS Applied Materials \& Interfaces 2017, 9, 14093-14102.

44. Li, L.; Liu, Y.; Zhao, X.; Lin, Z.; Wong, C.-P. Uniform Vertical Trench Etching on Silicon with High Aspect Ratio by Metal-Assisted Chemical Etching Using Nanoporous Catalysts. ACS Applied Materials \& Interfaces 2014, 6, 575-584.

45. Mallavarapu, A.; Ajay, P.; Sreenivasan, S. V. Enabling Ultrahigh-Aspect-Ratio Silicon Nanowires Using Precise Experiments for Detecting the Onset of Collapse. Nano Letters 2020, 20, 7896-7905.

46. Faustini, M.; Grosso, D. Self-assembled inorganic nanopatterns (INPs) made by sol-gel dip-coating: Applications in nanotechnology and nanofabrication. Comptes Rendus Chimie 2016, 19, 248-265.

47. Faustini, M.; Grenier, A.; Naudin, G.; Li, R.; Grosso, D. Ultraporous nanocrystalline TiO 2based films: Synthesis, patterning and application as anti-reflective, self-cleaning, superhydrophilic coatings. Nanoscale 2015, 7, 19419-19425.

48. Chang, S. W.; Chuang, V. P.; Boles, S. T.; Ross, C. A.; Thompson, C. V. Densely packed arrays of ultra-high-aspect-ratio silicon nanowires fabricated using block-copolymer lithography and metal-assisted etching. Advanced functional materials 2009, 19, 2495-2500.

\section{TOC graphic}




\section{Oxide}

\section{Mietal Assisted Chemical Etching}

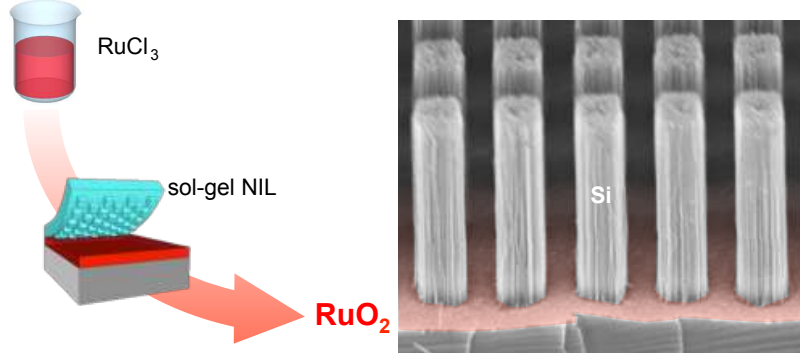

